\title{
An effective in situ reduction strategy assisted by supercritical fluids for the preparation of graphene -polymer composites
}

\author{
Suchithra Padmajan Sasikala, ${ }^{1 *}$ Wilfrid Neri, ${ }^{2}$ Philippe Poulin, ${ }^{2 *}$ and Cyril Aymonier ${ }^{1 *}$ \\ ${ }^{1}$ CNRS, Univ. Bordeaux, ICMCB, UPR 9048, 33600, France \\ ${ }^{2}$ Centre de Recherche Paul Pascal -CNRS, University of Bordeaux, 33600, France \\ $\ddagger$ Current affiliation: Department of Material Science and Engineering, Korea Advanced Institute of Science and Technology KAIST, \\ Daejeon 34141, Republic of Korea
}

\begin{abstract}
The chemical/thermal in situ reduction of graphene oxide (GO) in GO-polymer composite is consistently challenged by the presence of undesirable chemical residues/temperature degradation restriction of the polymer. In order to tackle this problem, an effective in situ supercritical fluid reduction strategy comprising of supercritical $\mathrm{CO}_{2}$ and ethanol binary system under $\mathrm{N}_{2}$ atmosphere was developed by stepwise comparison of different reduction methods for graphene oxide-polyvinyl alcohol (GO-PVA) composite films. The resulting rGO-PVA composite films comprising of $10 \mathrm{wt} \%$ rGO showed an electrical conductivity of $51.7 \mathrm{~S} / \mathrm{m}$-and Young's modulus of $3.1 \mathrm{GPa}$. Different weight loadings of GO in the polymer composite films were found to affect the electrical and mechanical properties of the resulting rGO-polymer films. The in situ supercritical fluid reduction strategy was demonstrated further for successfully obtaining rGO-polyethylene glycol films (rGO-PEG) and rGO-PVA fiber.
\end{abstract}

\section{Introduction}

Graphene in particular in monolayer state has remarkable properties such as high mechanical strength, elasticity, optical transparency, electrical and thermal conductivity, gas impermeability, and environmental stability [[1], [2], [3], [4], [5], [6]]. Incorporation of graphene into a polymer matrix should allow the utilization of these appealing properties for a wide range of applications such as conductive nanocomposites for organic electronics, flexible electronics, actuators, energy harvesting, sensors, safety systems and micro-electro mechanical systems [[7], [8], [9], [10]]. In order to achieve these applications, graphene should be homogeneously dispersed throughout the polymer matrix so that an effective interfacial load transfer exists between the polymer and the graphene sheets. However, graphene is difficult to disperse in classical solvents and polymers without the use of surfactants/chemical functionalization. This characteristic of graphene in fact limits its direct use in synthesizing graphene-polymer composites. 
A variety of techniques such as in situ polymerization, melt mixing and solution casting with ultrasonication mixing has been reported for the synthesis of graphene-polymer composites, which are however limited by nonuniform and low graphene loading $(<1 \mathrm{wt} \%)$ [11]. Another straight forward approach is to use graphene oxide (GO) instead of graphene to synthesize graphene-polymer composites. The abundant oxygenated functional groups in GO provide excellent dispersion and processing ability with polar solvents and hydrophilic polymers. Therefore, it is very easy to make homogenous GO-polymer composites in desired forms such as powder/film/fiber with hydrophilic polymers. The GO should be reduced either ex situ or in situ in the polymer composite to be able to make use of the superior electrical properties of graphene, without which GO is limited to a mechanically stabilizing passive component for the polymers [[12], [13], [14]]. Similar to graphene, rGO also is poorly processable to form homogenous polymer composites and hence ex situ reduction of GO to rGO, followed by composite formation with polymer is not efficient. In this scenario, in situ reduction of GO in GOpolymer composite would be much more convenient and practical. Nevertheless in this case, the maximal reduction temperature is generally limited to the temperature that the polymer matrix can sustain without being degraded [15]. This is again a strong limitation because a significant level of reduction of GO can be achieved only at high temperatures. As a consequence, the electronic properties of low temperature reduced composite films are not satisfactory. Another method is to utilize chemical reducing agents in a GO-polymer latex solution to reduce GO and swell the structure [16]. Composite formation and in situ chemical reduction of GO can be also achieved through coagulation process [17]. In all existing chemical approaches that are found to be effective in reducing GO, the systems have to be washed to remove reducing components and reaction byproducts, making chemical approaches more tedious and time consuming.

Here, we demonstrate a facile and efficient strategy that overcomes all the above limitations in the synthesis of rGO-polymer composite films. We developed an in situ reduction method for GO in polymer nanocomposite film using supercritical $\mathrm{CO}_{2}+$ ethanol binary system (Fig. 1). This method provides an efficient reduction way while keeping the temperature well below the degradation temperature of the polymer and thus avoiding to affect the structure of the composite film. The method is scalable and environmentally friendly and the as obtained freestanding rGO-polymer film/fiber show excellent electronic conductivity and mechanical stability. 


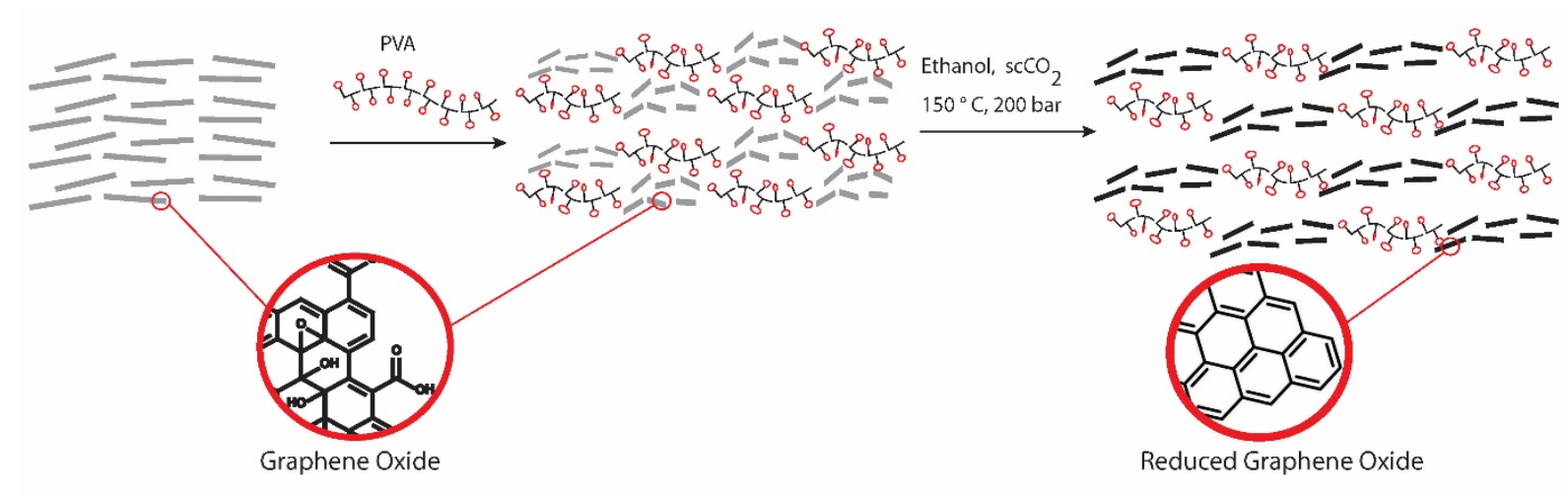

Figure 1. Schematic representation of synthesis of rGO-polymer composite via supercritical fluid assisted reduction of graphene oxide-polymer film/fiber.

\section{Experimental Section}

\section{Preparation of GO-Polymer film}

Graphene Oxide (GO) was purchased from Graphenea (Spain) as a suspension with a concentration of $4 \mathrm{mg} / \mathrm{ml}$ in water. Polyvinyl alcohol (PVA) with molecular weight of $195 \mathrm{~K}$ (98\%) and Polyethylene glycol (PEG) with molecular weight of $20 \mathrm{~K}$ were purchased from Sigma Aldrich. We have prepared and used aqueous PVA/PEG solutions of concentration $40 \mathrm{mg} / \mathrm{ml}$ during overall process. A series of GO-polymer composites with desired weight percentages (ranging from 0.5 to $20 \mathrm{wt} \%$ of GO) were prepared by mixing definite weights of GO and PVA/PEG aqueous suspensions. The mixture was subjected to mild ultrasonication for $30 \mathrm{~min}$ and then slowly but consistently stirred for at least $5 \mathrm{~h}$ to get a homogenous dispersion. The as prepared GO-PVA composite suspension was then poured into a teflon petri dish and allowed to dry at $50{ }^{\circ} \mathrm{C}$ for $48 \mathrm{~h}$. The dried composite was then peeled off from the petri dish to get GO-polymer film.

\section{Preparation of GO-PVA fiber}

A syringe pump was used to inject (at a constant rate set at $6 \mathrm{~mL} / \mathrm{h}$ ) the desired concentration of GO-PVA solution into a coagulation bath $\left(320 \mathrm{~g} / \mathrm{L}\right.$ sodium sulfate saturated solution) maintained at $40^{\circ} \mathrm{C}$. At the outlet of the syringe needle, the GO-PVA solution coagulated instantly to form a solid filament. The fibers were then allowed to flow through a washing bath for removing the salt residues present in the fiber after the coagulation process. As PVA is soluble in water, the washing bath cannot be composed only by water; otherwise, the wet fiber will stretch too much and end up by breaking. The addition of sodium tetraborate at $1 \mathrm{wt} \%$ in the washing bath allowed 
overcoming this problem. The fiber was then dried with the help of two infrared lamps, at a temperature of $75^{\circ} \mathrm{C}$, and finally collected on a winder rotating disk.

\section{In situ reduction of GO-polymer film/fiber}

The in situ reduction experiments were carried out in high temperature and high pressure reactors; a schematic of the reduction set-up is shown in Fig. S1. The reactor was purged with $\mathrm{N}_{2}$ for $1 \mathrm{~h}$ to remove the air trapped in the system, before all experiments unless otherwise stated. For the nearcritical ethanol reduction experiment, the dried GO-PVA films were transferred to the reactor containing $30 \mathrm{ml}$ of ethanol. The reactor was tightly closed and heated to a temperature of $150^{\circ} \mathrm{C}$ and a pressure of $200 \mathrm{bar}$ for desired time. In the case of in situ reduction experiments with $s c \mathrm{CO}_{2}+$ ethanol binary system, the GO-polymer film/fiber were firstly immersed in ethanol for 10-20 min, and the wet samples with a maximum of $1 \mathrm{ml}$ ethanol were transferred to the high temperature and high-pressure reactor of $50 \mathrm{ml}$ capacity. Then $\mathrm{CO}_{2}$ was filled in the reactor up to a pressure of 40-60 bar and heated up to the desired temperature from $100-150^{\circ} \mathrm{C}$. The pressure of the reactor is increased with the temperature. At this point, the pressure in the reactor was maintained at 200-250 bar by adjusting a side valve. The reaction was allowed to progress for 1-3 h. After a given time, reaction was terminated by removing the heating zone and gradually submerging the hot reactor into the ice-cold water bath. The outlet valve of the reactor was opened to flush out the gas when the reactor temperature reached below $50{ }^{\circ} \mathrm{C}$. For comparison GO-polymer films were reduced as described earlier with only $s c \mathrm{CO}_{2}$ and also thermally reduced in a conventional tube furnace in both inert and ambient conditions.

\section{Results and Discussion}

Because of the numerous hydrophilic functional groups on its surface, GO is very compatible with hydrophilic polymers like PVA. Thermogravimetric analysis (TGA) were conducted for GO, PVA, and GO-PVA in order to investigate the decomposition temperature of polymer (Fig. 2a). GO due to the abundant oxygen functionalities and trapped water molecules showed significant weight loss of $40.0 \%$ between 100 and $250{ }^{\circ} \mathrm{C}$. PVA showed a weight loss of $8.0 \%$ between 100 and $240{ }^{\circ} \mathrm{C}$, attributed to the loss of absorbed water and a drastic weight loss $>240{ }^{\circ} \mathrm{C}$ indicating the decomposition of the polymer. This is in accordance with the previous reports of chemical degradation of PVA resulting from carbon-carbon bond scission in the polymeric backbone above $250{ }^{\circ} \mathrm{C}[18,19]$. Further, we performed an isothermal TGA of the samples at $180^{\circ} \mathrm{C}$ for a maximum time of $6 \mathrm{~h}$. As shown in Fig. 2b, while GO and GO-PVA showed a weight loss of 17.4 and $9.1 \%$, respectively, PVA showed a small weight loss of $4.0 \%$ when the reaction progressed up to $6 \mathrm{~h}$. Thus, we fixed the reduction temperature in this study to a temperature $\left(150^{\circ} \mathrm{C}\right)$ well below the decomposition temperature of PVA $\left(225^{\circ} \mathrm{C}\right)$, unless otherwise stated. 

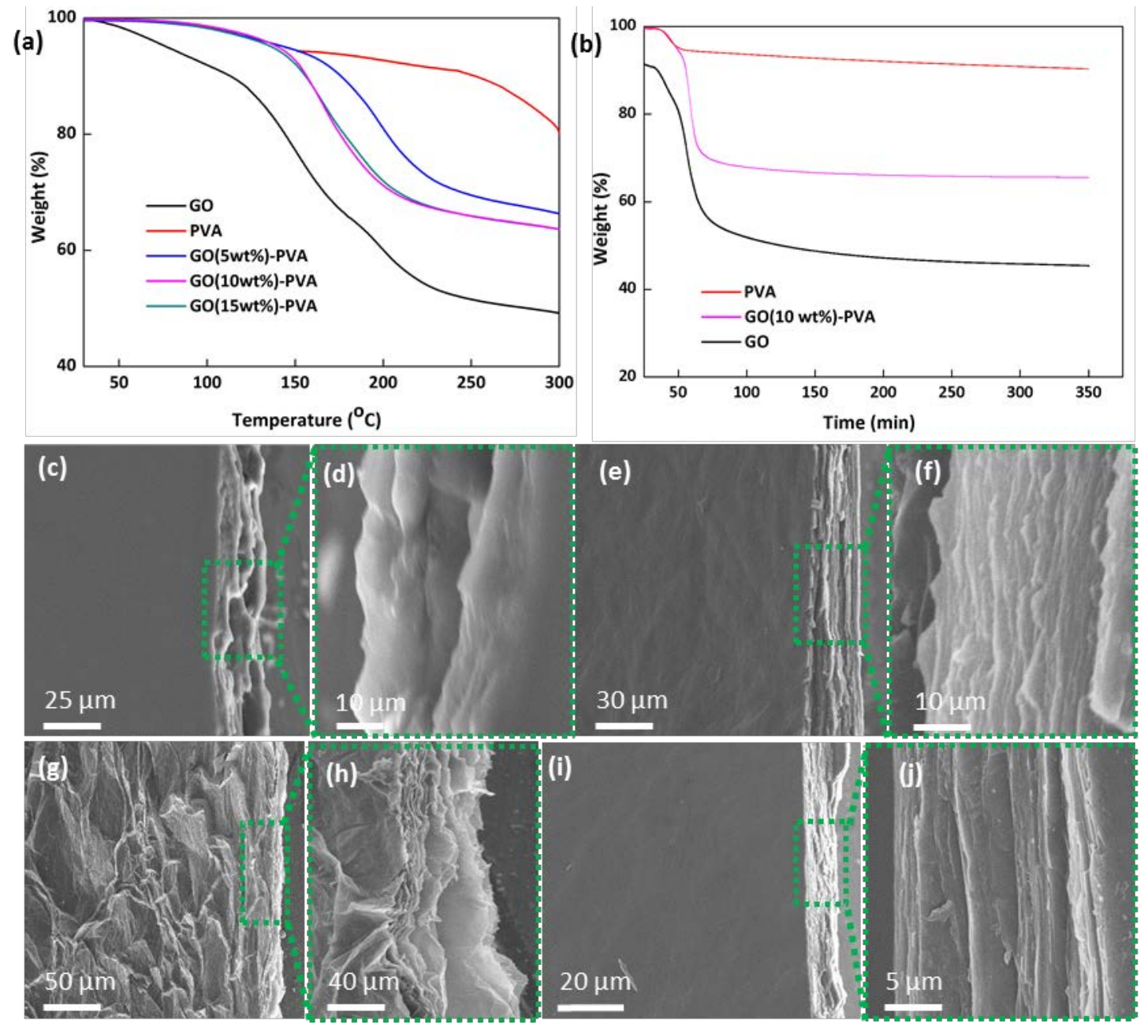

Figure 2 (a) TGA of GO, PVA and GO-PVA composite with different loading of GO. (b) Isothermal TGA at $180{ }^{\circ} \mathrm{C}$ of GO, PVA and GO-PVA.SEM surface and cross-sectional image of (c,d) PVA, (e,f) GO-PVA, and rGO-PVA composite films obtained by (g,h) nearcritical ethanol and (i,j) $s c \mathrm{CO}_{2}+$ ethanol binary system treatment.

Supercritical ethanol is validated earlier for its proton donating and subsequent dehydration reaction with GO [20,45]. However since the critical temperature of ethanol (Tc: $241^{\circ} \mathrm{C}$ and Pc: $62.7 \mathrm{bar}$ ) is above the temperature limit of decomposition of PVA, we have employed the nearcritical conditions for ethanol (T: $150^{\circ} \mathrm{C}$ and $\mathrm{P}$ : 200 bar). The nearcritical ethanol reduction of GO-PVA solution have resulted in reduction of GO. Nevertheless, concurrent agglomeration and separating out of reduced GO (rGO) from the PVA matrix also occurred. In order to tackle this problem, we employed an alternative strategy in which GO-PVA films are made by simple solution casting of GO-polymer composite solutions as a first stage followed by the in situ reduction of GO in the dried composite films. Information about size and homogeneity of the films can be acquired from the scanning electron microscopy (SEM) images. The average thickness of films ranged from 30 to $50 \mu \mathrm{m}$. A morphology comparison of PVA film and GO-PVA film is given in Fig. 2c-f. As expected, GO-PVA films are found to be electrically insulating due to the oxidized defects of GO and the intrinsic insulating nature of the polymers. In order to restore Suchithra Padmajan Sasikala, Wilfrid Neri, Philippe Poulin, Cyril Aymonier. An effective in situ reduction strategy assisted by supercritical fluids for the preparation of graphene - polymer composites. Carbon, Elsevier, 2018, 139, pp.572-580. 〈10.1016/j.carbon.2018.06.076〉. 〈hal-01865407〉 
the electrical conductivity of GO in the polymer composite films, we immersed the films in ethanol in a closed high-pressure reactor and increased the temperature and pressure of the reactor to $150{ }^{\circ} \mathrm{C}$ and $200 \mathrm{bar}$, respectively. The analysis of the film after this nearcritical ethanol ( $n c E t O H)$ treatment for $2 \mathrm{~h}$, showed favorable reduction of GO, but the homogeneity of the films had been lost considerably due to swelling in the ethanol (Fig. 2g and h). Thus we modified our experimental protocol such that the films are only allowed to wet in ethanol for a short span of time which is then subjected to supercritical $\mathrm{CO}_{2}\left(s c \mathrm{CO}_{2}, \mathrm{Tc}: 31^{\circ} \mathrm{C} \mathrm{Pc:} 73.8\right.$ bar $)$ treatment in the high pressure reactor at $150^{\circ} \mathrm{C}$ and 200 bar (Please see the details in Experimental Section). Since the ethanol is soluble in $s c \mathrm{CO}_{2}$, and also the diffusive power of $s c \mathrm{CO}_{2}$ is very high, we can anticipate that $s c \mathrm{CO}_{2}$ helps ethanol on the surface to diffuse into the entire volume of film and reduce GO to restore the graphene crystal lattice without decomposing the polymer [46,47]. Gong et al. have validated the reduction mechanism of ethanol for GO under thermal conditions, with the help of in situ infrared absorption spectroscopy, ab initio molecular dynamics calculations and density functional theory [21]. According to authors, thermal annealing (as low as $100{ }^{\circ} \mathrm{C}$ ) causes the formation of bare etch holes in the GO crystal lattice. Ethanol in the interlayers of GO integrates into these etch holes and reacts with neighboring oxygenated groups such as carbonyls or ethers to reopen the hexagonal carbon ring for further carbon incorporation. Thus, ethanol not only removes the oxygenated groups but also fosters the graphitization. This kind of observation of scavenging of holes in GO crystal lattice by ethanol is also seen under laser irradiation [22]. As shown in Fig. 2i and j, the homogeneity of GO-PVA films were well maintained after the supercritical reduction.

Fig. 3a shows the XRD patterns of GO, rGO, PVA and GO/PVA nanocomposite films before and after supercritical reduction (rGO-PVA). A diffraction peak in the XRD spectrum at $10.4^{\circ}(0.85 \mathrm{~nm})$ is typical in the case of GO which represents oxygen containing functional groups in the interlayers of stacked GO sheets in the GO film. After reduction treatment, many oxygen containing groups will be removed from GO and as a result the interlayer distance decreases significantly as observed in the spectrum of rGO that the diffraction peak is shifted to $23.6^{\circ}(0.37 \mathrm{~nm})[23]$. However this typical diffraction peak of $\mathrm{GO} / \mathrm{rGO}$ is absent in the polymer composite (GOPVA) film which showed the diffraction peak of pure PVA at $19.4^{\circ}$.This can be regarded as a sign of an individual and homogenous integration of monolayer GO sheets into the polymer matrix, so that the periodic structure of stacked graphene oxide is lost [[24], [25], [26], [27]]. After the supercritical reduction of composite film, the characteristic PVA diffraction peak broadened. Fig. S2 shows the XRD spectra of neat PVA films before and after supercritical reduction. The characteristic diffraction peak at $19.4^{\circ}$ is sharper after the supercritical treatment. This peak sharpening can be regarded as an increased crystallization [30]. The absence of such increased crystallinity in presence of rGO suggests that the rGO impart steric barrier for PVA crystal growth [16,44].

Suchithra Padmajan Sasikala, Wilfrid Neri, Philippe Poulin, Cyril Aymonier. An effective in situ reduction strategy assisted by supercritical fluids for the preparation of graphene - polymer composites. Carbon, Elsevier, 2018, 139, pp.572-580. $\langle 10.1016 /$ j.carbon.2018.06.076 $\rangle$. 〈hal-01865407〉 

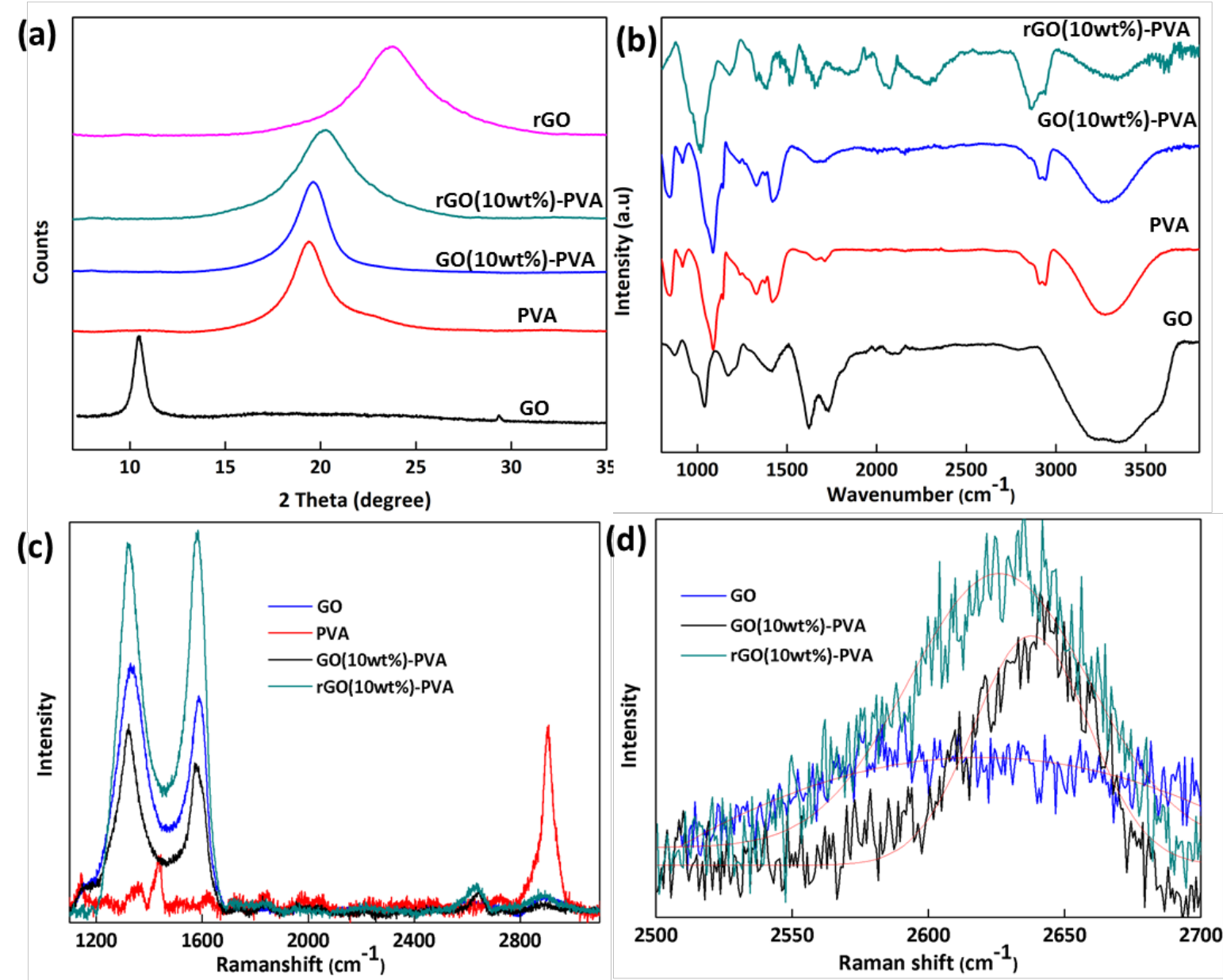

Figure 3(a). XRD of GO, PVA, GO-PVA, rGO-PVA and rGO (b) IR spectra of GO, PVA, GO-PVA and rGO-PVA (c) Raman spectra of GO, PVA, GO-PVA and rGO-PVA films, (d) Magnified 2D peak of GO, GO-PVA and rGO-PVA.

In the IR spectrum of GO (Fig. 3b), the broad peak centered around $3364 \mathrm{~cm}^{-1}$ and broadened up to $3600 \mathrm{~cm}^{-1}$ indicates the simultaneous presence of free hydroxyl groups and hydrogen bonded -O-H stretch. On the contrary, this peak is sharpened in the IR spectra of PVA indicative of strong hydrogen bonding interaction between PVA molecules. The intensity of sharp peak around $3300 \mathrm{~cm}^{-1}$ is found to decrease in GO-PVA compared to that of PVA. This can be attributed to the dissociation of hydrogen bonding in hydroxyl group of PVA and hydrogen bond formation between hydroxyl groups of GO and PVA chain [25]. After supercritical reduction of GO-PVA film (rGO-PVA), we can observe a reduction of the intensity in this peak, indicative of removal of hydroxyl functionalities from the composite. In addition, the band around $1100 \mathrm{~cm}^{-1}$ which can be assigned to the $-\mathrm{C}-\mathrm{OH}$ stretching displayed a similar behavior, indicating that even though the hydroxyl functionalities are reduced in the GO-PVA composite, still an extent of hydrogen bonded hydroxyl group exists in the film.

The extent of reduction of GO in the composite is further evaluated by Raman spectroscopy. For comparison purposes, the Raman spectra of PVA and GO are also shown in Fig. 3c. The Raman spectrum of PVA displayed Suchithra Padmajan Sasikala, Wilfrid Neri, Philippe Poulin, Cyril Aymonier. An effective in situ reduction strategy assisted by supercritical fluids for the preparation of graphene - polymer composites. Carbon, Elsevier, 2018, 139, pp.572-580. 〈10.1016/j.carbon.2018.06.076〉. 〈hal-01865407〉 
a characteristic band at $2909 \mathrm{~cm}^{-1}$, which can also be found in GO-PVA and rGO-PVA composite films. In GO and GO-PVA characteristic D band $\left(1337 \mathrm{~cm}^{-1}\right)$ and $\mathrm{G}$ band $\left(1588 \mathrm{~cm}^{-1}\right)$ can be shown (Fig. 3c). The ratio of intensity of the D to $\mathrm{G}$ band (ID/IG) is used to measure the degree of disorder, and number and average size of the $\mathrm{sp}^{2}$ domains in graphene materials. The ID/IG ratios for GO and GO-PVA were found to be $1.2 \pm 1.0$. It is to be noted that the basal plane of GO is heavily defected with epoxide groups and hydroxyl groups. Many carboxyl groups are also present in the edge sites [28]. After the reduction treatment many epoxide/hydroxyl/carboxyl groups were removed leading to the recovery of distorted six-fold aromatic ring, and carbon lattice returns to graphitic state resulting in the activation of D peak. Depending on the extent of defect sites, number and size of recovered $\mathrm{sp}^{2}$ domains the ID/IG ratio can increase or decrease [14]. After the supercritical reduction, ID/IG value decreased to $0.95 \pm 0.1$ which can be accounted as the formation of new graphitic $\mathrm{sp}^{2}$ domains. Notably, in the spectrum of rGO-PVA, the D, G and 2D peaks shifted to lower wave numbers of 1321,1581 and $2626 \mathrm{~cm}^{-1}$, respectively (Fig. 3c and d). This indicates the recovered hexagonal network of carbon atoms and confirms the successful reduction of GO to rGO.

We have also conducted XPS analysis of GO films without polymer after supercritical reduction maintaining the same experimental conditions as in the case of GO-PVA films in order to have an insight on the extent of deoxygenation by the supercritical reduction (Fig. S3). As shown, after supercritical reduction C/O ratio increased from 1.89 (GO) to 5.94 (rGO) indicating significant deoxygenation of GO by the reduction conditions employed.

\section{Mechanical Test of rGO-PVA films}

H-bonding helps in the interfacial adhesion between GO and polymers and offers effective load transfer which in turn enhances the mechanical properties of the composite [29]. The mechanical performance of composite films is assessed and compared with pure PVA film in order to analyze the mechanical stability (Table S1). Fig. 4a represents the stress-strain relationship for nanocomposite films for a range of GO/rGO weight fractions. The mechanical strength of the GO-PVA and rGO-PVA films is found to be significantly increased as that of PVA film. Both tensile stress and elongation at break had increased for GO-PVA and rGO-PVA compared to PVA.

Suchithra Padmajan Sasikala, Wilfrid Neri, Philippe Poulin, Cyril Aymonier. An effective in situ reduction strategy assisted by supercritical fluids for the preparation of graphene - polymer composites. Carbon, Elsevier, 2018, 139, pp.572-580. $\langle 10.1016 /$ j.carbon.2018.06.076 $\rangle$. 〈hal-01865407〉 

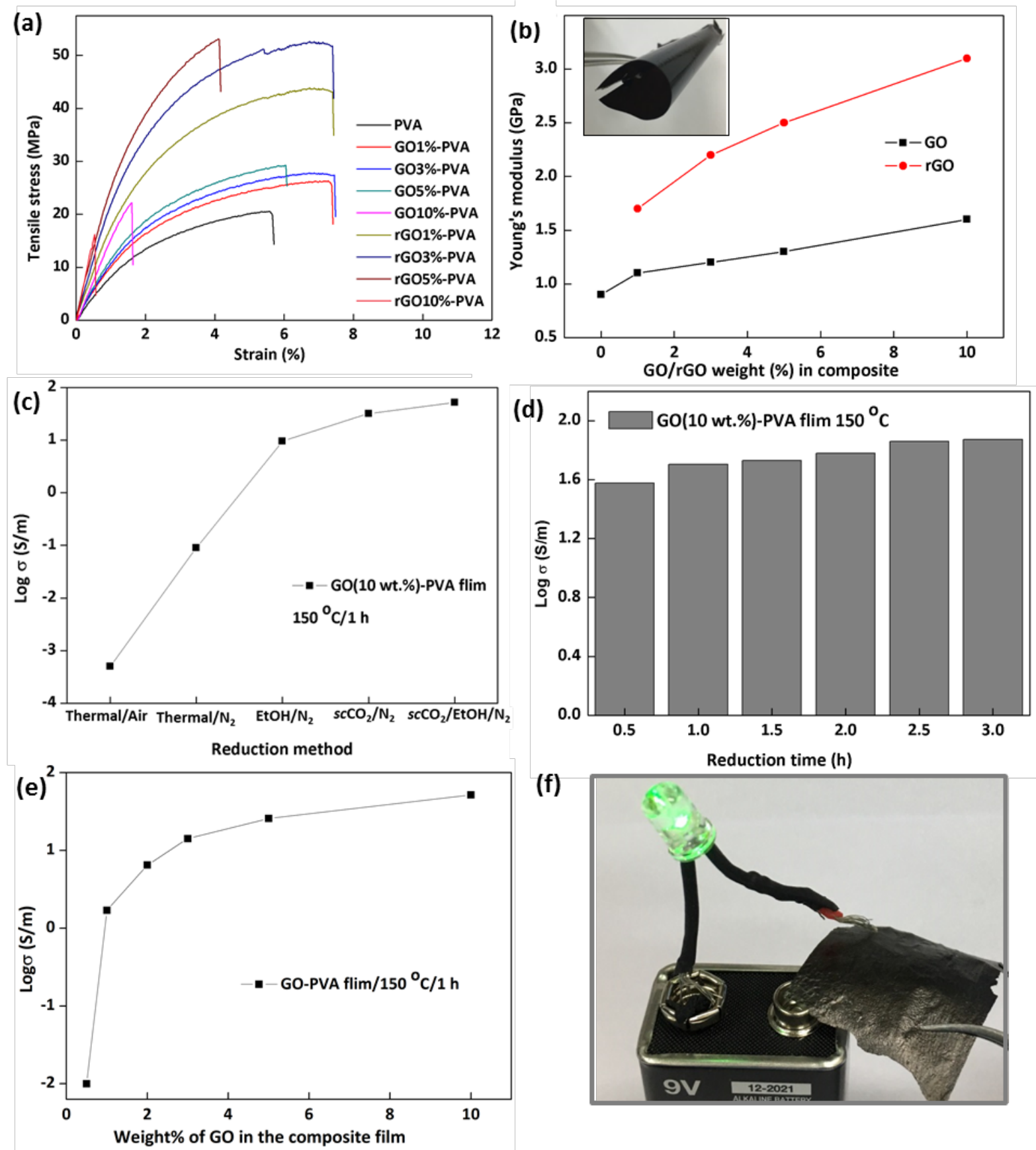

(f)

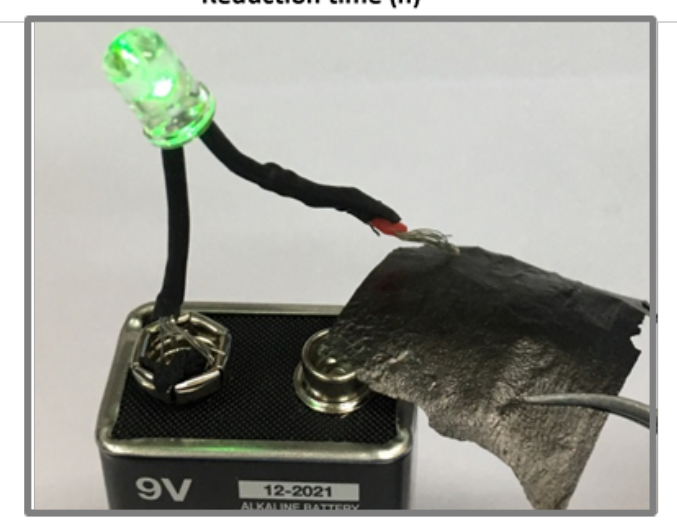

Figure 4 (a) Representative stress-strain curves as a function of GO/rGO loading and (b) Increase in Young's modulus of the composites with GO weight\%. Inset of (b) is a photograph of rGO (3wt\%)-PVA film demonstrating the mechanical flexibility of the film. (c) Electrical conductivity of rGO-PVA film containing $10 \mathrm{wt} \% \mathrm{rGO}$ after different reduction methods at $150{ }^{\circ} \mathrm{C}$ for $1 \mathrm{~h}$, (d,e) Increase of electrical conductivity of rGO-PVA film containing $10 \mathrm{wt} \% \mathrm{rGO}$ after supercritical reduction using $s c \mathrm{CO}_{2}+$ ethanol binary system at $150^{\circ} \mathrm{C}$ with increasing (d) reduction time and (e) rGO loading, (f) Photograph of rGO-PVA film used as a conductive element in the circuit to light a green LED.

In the case of GO-PVA films, there has been a maximum of 34\% increase in the tensile strength as compared to pure PVA film with only $1 \mathrm{wt} \% \mathrm{GO}$ in the composite film. The tensile strength has been found to increase further 
up to a maximum of $48.4 \%$ when the loading of GO increased to $3 \mathrm{wt} \%$. The corresponding elongation at break has increased to 38.9\% compared to pure PVA. However further increase of GO up to $5 \mathrm{wt} \%$ found to decrease the elongation at break compared to GO-PVA containing $3 \mathrm{wt} \%$ GO. The increase in strain \% was limited to 7.7\% for GO (5 wt\%)-PVA compared to PVA. Nevertheless, the tensile strength of GO (5 wt \%)-PVA has increased by $53.3 \%$ compared to PVA. Notably, when the concentration of GO has increased up to $10 \mathrm{wt} \%$, the mechanical performance of the composite significantly decreased with respect to pure PVA film. The elongation at break has decreased from $5.6 \%$ of PVA to $1.7 \%$ for GO (10 wt $\%)$-PVA. The reinforcement at low concentration is presumably due to strong adhesion of the GO particles with polymer through H-bonding. However, when the concentration of GO is increased, neighboring sheets interact and may effectively act as aggregates which may lead to inhomogeneous stress distribution in the composite. This inhomogeneity makes the composite more brittle. Notably, the tensile strength of neat PVA film range from $17 \mathrm{MPa}$ to $100 \mathrm{MPa}$ in the literature [[29], [30], [31], [32], [33], [34], [35]] and the measured mechanical properties of our GO-PVA composites are somewhat lower than better values reported in the literature. Nevertheless, the degree of improvement of mechanical properties of PVA films after incorporation of GO is comparable to other reports [[31], [32], [33], [34], [35]]. These variations can be understood considering that mechanical properties depend on many variables such as processing conditions, type (molecular weight in the case of polymer, aspect ratio in the case of graphene oxide), concentration (of polymer and graphene oxide) and source of materials (purity, manufacture).

Interestingly, the tensile strength of the composite film was enhanced after supercritical reduction treatment by 59.7 and $82.2 \%$ for 1 and $3 \mathrm{wt} \% \mathrm{rGO}$, respectively, compared to the corresponding GO-PVA. This can be related to the increased PVA crystallinity after the reduction process which may increase the reinforcement effect of rGO with the PVA matrix. It can also be due to the increase of Young's modulus of the sheets after reduction. However, it can be noticed that at higher GO concentration $(10 \mathrm{wt} \%)$ the tensile strength of rGO-PVA film is very poor. The materials become brittle again because of the large concentration of reinforcing particles. Fig. 4(b) represents the relative enhancement of Young's modulus of the composites. The modulus has increased linearly with increase in GO/rGO wt\% in the composite. The tensile modulus of the pure PVA is $0.9 \mathrm{GPa}$ which has increased by $78 \%$ and $244 \%$ for the composite containing $10 \mathrm{wt} \% \mathrm{GO}$ and $\mathrm{rGO}$, respectively. It is normal that a comparatively stronger inorganic material such as GO and rGO, when added to a soft organic polymer like PVA will enhance the Young's modulus value of the resulting composites. It is also expected that rGO display a better reinforcement because of its greater stiffness compared to GO.

\section{Electrical Conductivity Test}

Suchithra Padmajan Sasikala, Wilfrid Neri, Philippe Poulin, Cyril Aymonier. An effective in situ reduction strategy assisted by supercritical fluids for the preparation of graphene - polymer composites. Carbon, Elsevier, 2018, 139, pp.572-580. $\langle 10.1016 /$ j.carbon.2018.06.076 $\rangle$. 〈hal-01865407〉 
While graphene is a good conductor of electricity $\left(10^{8} \mathrm{~S} / \mathrm{m}\right)$, GO is electrically insulating. Since PVA is also electrically insulating $\left(5.3 \times 10^{-12} \mathrm{~S} / \mathrm{m}\right)$, the GO-PVA composite is electrically insulating as well. Thorough reduction of GO in the composite to rGO should make the resulting composite electrically conductive. In this study, we tested different reduction methods such as thermal reduction under $\mathrm{N}_{2}$, nearcritical ethanol (ncEtOH), supercritical $\mathrm{CO}_{2}\left(s c \mathrm{CO}_{2}\right)$, and $s c \mathrm{CO}_{2}+$ ethanol binary system reduction treatments to regain the electrical conductivity of GO-PVA film and their respective electrical conductivity values are shown in Fig. 4c. Notably, all above listed reduction methods have changed the colour of the film from brown to black, which can be accounted as partial restoration of the $\pi$-conjugation network within the rGO sheets by removing many hydroxyl/carboxyl functionalities originally present in GO. However, in order to achieve significant improvement of electrical conductivity, $\pi$-conjugation should be restored by removing most of the epoxide groups as well. As shown, the $s c \mathrm{CO}_{2}+$ ethanol binary system reduction method gives the best electrical conductivity values among the tested methods. It has been found that the GO-PVA films became well-conductive after being reduced (rGOPVA) for a minimum time of $30 \mathrm{~min}$, and the electrical conductivity value has increased with increasing reduction time (Fig. 4d). Nevertheless, increasing the reduction time beyond $2 \mathrm{~h}$ is found to demerit the mechanical stability of the rGO-PVA film. The films became brittle presumably due to the increased crystallinity. The electrical conductivity of the rGO-PVA film was found to increase with increasing initial GO weight\% in the composite also (Fig. 4e). A photographic illustration is provided in Fig. $4 \mathrm{f}$ to demonstrate the recovered electrical conductivity of rGO-PVA film after supercritical reduction, which used as a conductive element in the circuit with $9 \mathrm{~V}$ battery to light a green light emitting diode (LED). The conductivity of the rGO-PVA film increased from 0.01 to $51.7 \mathrm{~S} / \mathrm{m}$ as the rGO content increases from $0.5 \mathrm{wt} \%$ to $10 \mathrm{wt} \%$. The sharp rise of electrical conductivity as a function of GO weight\% indicates a percolation type behavior with a percolation threshold between 1 and $2 \mathrm{wt} \%$, corresponding to a volume fraction typically between 0.5 and $1 \mathrm{vol} \%$, assuming a density of $1.8 \mathrm{~g} / \mathrm{cm}^{3}[28,36]$. We note that this percolation threshold is much higher than the threshold expected for randomly oriented platelets of large aspect ratio. The percolation threshold should be of the order of $t / D$ where " $t$ " and " $D$ " are the thickness and diameter of the GO flakes, respectively. Here, this threshold would be theoretically less than 0.1 vol\% considering the giant anisotropy of GO materials. The greater value of percolation threshold presently observed suggests that the flakes are oriented, as a result of the tendency of GO particles to form liquid crystal phases $[37,38]$.

Further we successfully tested the supercritical fluid assisted reduction method to produce rGO-PEG films, which, similarly to rGO-PVA films, showed increased electrical conductivity values with increase in rGO content in the composite (Fig. 5a-c). The rGO-PEG films which contain $10 \mathrm{wt} \%$ of GO showed an electrical conductivity value of $15.1 \mathrm{~S} / \mathrm{m}$, which has increased to $24.9 \mathrm{~S} / \mathrm{m}$ when GO loading increased to $20 \mathrm{wt} \%$. Raman spectrum of rGO- 
PEG film is compared with GO-PEG film in Fig. S4, which showed considerable decrease in ID/IG value after supercritical reduction similar to rGO-PVA film. In addition, this method is found to effectively reduce in-situ GO in rGO-PVA fibers also (Fig. 5d-f).
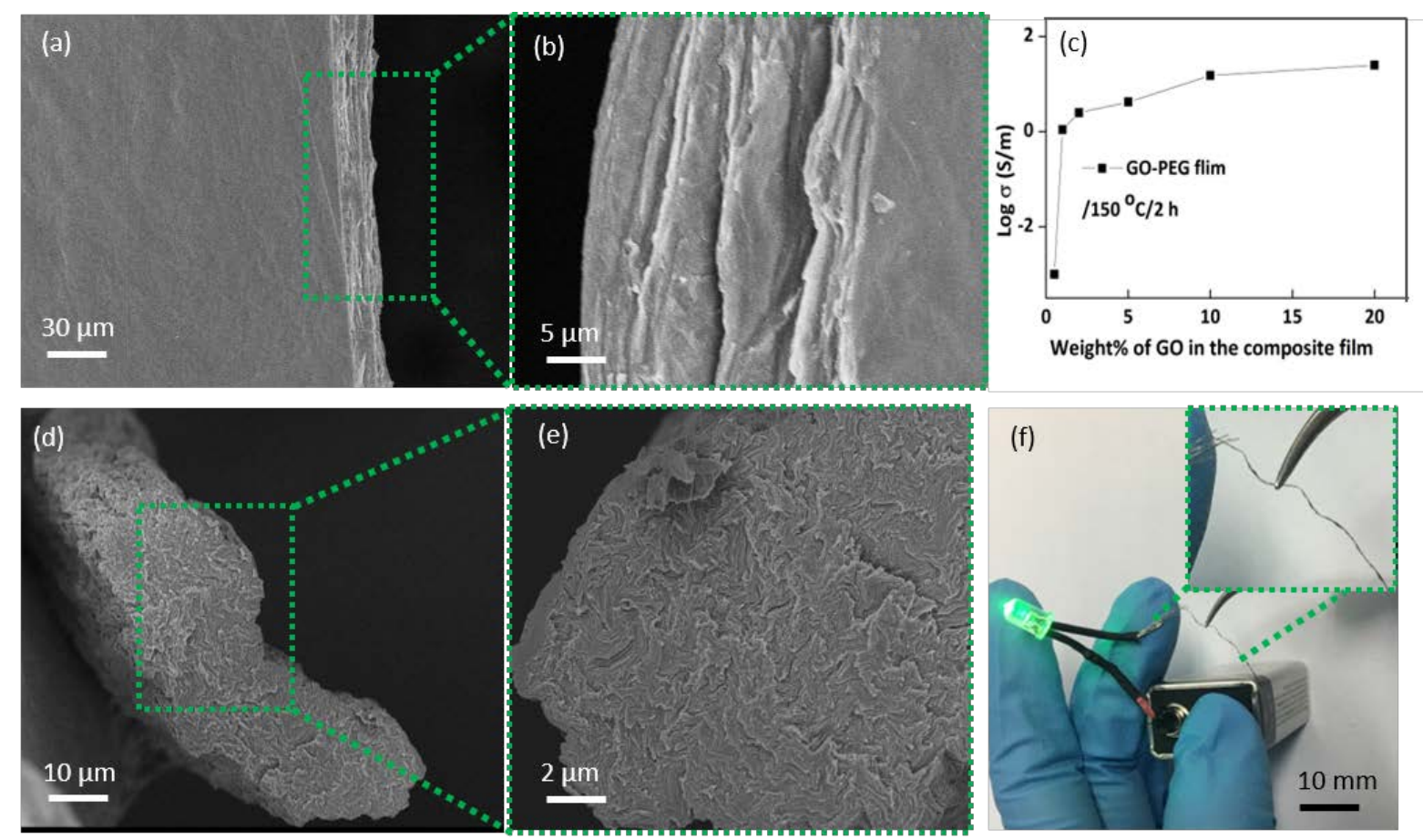

Figure 5. (a) Surface and (b) lateral SEM image of rGO-PEG film, (c) Increase of electrical conductivity of rGO-PEG film after supercritical reduction using $s c \mathrm{CO}_{2}$ and $n c E t O H$ at $150^{\circ} \mathrm{C}$ with increasing rGO loading, (d,e) Cross sectional SEM image of rGO-PVA fiber (f) photograph of rGO-PVA fiber used as a conductive wire in an electrical circuit to light an LED.

Note that, a direct comparison of effectiveness of a particular reduction method is difficult in graphene-polymer nanocomposites since various factors were found to influence the percolation threshold and electrical conductivity of resulting composite such as graphene loading, aspect ratio of graphene sheets, functionalization and aggregation of graphene, type of polymer, processing methods, wrinkles (in the case of film/fiber morphology) and homogeneity of the composite. Nevertheless, we compare in Table 1, the electrical conductivity and mechanical property of GO-PVA composites prepared by supercritical fluid assisted reduction method with other reported reduction methods in order to establish the effectiveness of this method for preparing conductive graphene-polymer composite with favorable mechanical properties. The reason for such enhanced properties can be accounted for the supercritical fluid assisted reduction method that we employed. Due to intrinsically high diffusive nature, $s c \mathrm{CO}_{2}$ can impregnate ethanol into the whole volume of the composite film which result in much effective reduction of the GO and at the same time the homogeneity of the composite film is also preserved. 
24. A. GhavamiNejad, S. Hashmi, H.-I. Joh, S. Lee, Y.-S. Lee, M. Vatankhah-Varnoosfaderani, F.J. Stadler. Network formation in graphene oxide composites with surface grafted PNIPAM chains in aqueous solution characterized by rheological experiments. Phys. Chem. Chem. Phys., 16 (2014), pp. 8675-8685.

25. Y. Shi, D. Xiong, J. Li, N. Wang. In situ reduction of graphene oxide nanosheets in poly(vinyl alcohol) hydrogel by $\mathrm{V}$-ray irradiation and its influence on mechanical and tribological properties. J. Phys. Chem. C, 120 (2016), pp. $19442-19453$.

26. H.M. Kim, J.K. Lee, H.S. Lee. Transparent and high gas barrier films based on poly (vinyl alcohol)/graphene oxide composites. Thin Solid Films, 519 (2011), pp. 7766-7771.

27. Z. Li, R.J. Young, I.A. Kinloch. Interfacial stress transfer in graphene oxide nanocomposites. ACS Appl. Mater. Interfaces, 5 (2013), pp. 456-463.

28. D.A. Dikin, S. Stankovich, E.J. Zimney, R.D. Piner, G.H.B. Dommett, G. Evmenenko, S.T. Nguyen, R.S. Ruoff. Preparation and characterization of graphene oxide paper. Nature, 448 (2007), p. 457.

29. J. Liang, Y. Huang, L. Zhang, Y. Wang, Y. Ma, T. Guo, Y. Chen. Molecular-level dispersion of graphene into poly(vinyl alcohol) and effective reinforcement of their nanocomposites. Adv. Funct. Mater., 19 (2009), pp. $2297-2302$.

30. X. Zhao, Q. Zhang, D. Chen, P. Lu. Enhanced mechanical properties of graphene-based poly (vinyl alcohol) composites. Macromolecules, 43 (2010), pp. 2357-2363.

31. Y. Xu, W. Hong, H. Bai, C. Li, G. Shi. Strong and ductile poly (vinyl alcohol)/graphene oxide composite films with a layered structure. Carbon, 47 (2009), pp. 3538-3543.

32. C. Bao, Y. Guo, L. Song, Y. Hu. Poly(vinyl alcohol) nanocomposites based on graphene and graphite oxide: a comparative investigation of property and mechanism. J. Mater. Chem., 21 (2011), pp. 13942-13950.

33. H.K.F. Cheng, N.G. Sahoo, Y.P. Tan, Y. Pan, H. Bao, L. Li, S.H. Chan, J. Zhao. Poly (vinyl alcohol) nanocomposites filled with poly (vinyl alcohol)-grafted graphene oxide. ACS Appl. Mater. Interfaces, 4 (2012), pp. 2387-2394.

34. X. Yang, L. Li, S. Shang, X.-m. Tao. Synthesis and characterization of layer-aligned poly (vinyl alcohol)/graphene nanocomposites. Polymer, 51 (2010), pp. 3431-3435.

35. S. Morimune, M. Kotera, T. Nishino, T. Goto. Uniaxial drawing of poly (vinyl alcohol)/graphene oxide nanocomposites. Carbon, 70 (2014), pp. 38-45.

36. C. Zamora-Ledezma, N. Puech, C.C. Zakri, E. Grelet, S.E. Moulton, G.G. Wallace, S. Gambhir, C. Blanc, E. Anglaret, P. Poulin. Liquid crystallinity and dimensions of surfactant-stabilized sheets of reduced graphene oxide. J. Phys. Chem. Lett., 3 (2012), pp. 2425-2430.

37. J. Yuan, A. Luna, W. Neri, C. Zakri, T. Schilling, A. Colin, P. Poulin. Graphene liquid crystal retarded percolation for new high-k materials. Nat. Commun., 6 (2015), p. 8700.

38. M. Mathew, T. Schilling, M. Oettel. Connectivity percolation in suspensions of hard platelets. Phys. Rev., 85 (2012), p. 061407.

39. I. Tantis, G.C. Psarras, D. TasisFunctionalized graphene-poly (vinyl alcohol) nanocomposites: physical and dielectric properties. Express Polym. Lett., 6 (2012).

40. R.K. Layek, S. Samanta, A.K. NandiThe physical properties of sulfonated graphene/poly(vinyl alcohol) composites. Carbon, 50 (2012), pp. 815-827.

41. T.N. Zhou, X.D. Qi, Q. Fu. The preparation of the poly (vinyl alcohol)/graphene nanocomposites with low percolation threshold and high electrical conductivity by using the large-area reduced graphene oxide sheets. Express Polym. Lett., 7 (2013).

42. H.J. Salavagione, G. Martínez, M.A. Gómez. Synthesis of poly (vinyl alcohol)/reduced graphite oxide nanocomposites with improved thermal and electrical properties. J. Mater. Chem., 19 (2009), pp. 5027-5032.

43. S. Mo, L. Peng, C. Yuan, C. Zhao, W. Tang, C. Ma, J. Shen, W. Yang, Y. Yu, Y. Min. Enhanced properties of poly (vinyl alcohol) composite films with functionalized graphene. RSC Adv., 5 (2015), pp. 97738-97745.

44. H.E. Assender, A.H. WindleCrystallinity in poly (vinyl alcohol). 1. An X-ray diffraction study of atactic PVOH. Polymer, 39 (1998), pp. 4295-4302.

45. S. Padmajan Sasikala, L. Henry, G. Yesilbag Tonga, K. Huang, R. Das, B. Giroire, S. Marre, V.M. Rotello, A. Penicaud, P. Poulin, C. Aymonier. High yield synthesis of aspect ratio controlled graphenic materials from anthracite coal in supercritical fluids. ACS Nano., 10 (2016), pp. 5293-5303. 
Consequently, high electrical conductivity can be achieved without sacrificing mechanical properties of the composites.

Table 1. Comparison of electrical conductivity of rGO-PVA films prepared through different reduction methods

\begin{tabular}{|c|c|c|c|c|c|}
\hline $\begin{array}{c}\text { Type of } \\
\text { Composite }\end{array}$ & Synthesis method & $\begin{array}{l}\text { Weight\% of } \\
\text { GO (wt \%) }\end{array}$ & Reduction method & $\begin{array}{c}\text { Electrical } \\
\text { conductivity } \\
(\mathrm{S} / \mathbf{m})\end{array}$ & Ref \\
\hline GO/PVA & $\begin{array}{c}\text { Solution mixing } \\
\text { followed by vaccum } \\
\text { filtration }\end{array}$ & 4 & $\begin{array}{l}\text { Thermal reduction, } \\
60{ }^{\circ} \mathrm{C} \text {, over night }\end{array}$ & 0.063 & [15] \\
\hline $\begin{array}{c}\text { Graphene/copo } \\
\text { lymer/PVA }\end{array}$ & $\begin{array}{l}\text { Solution casting } \\
\text { followed by hot } \\
\text { pressing at } 200{ }^{\circ} \mathrm{C}\end{array}$ & 5 & ------------------- & $10^{-4}$ & [39] \\
\hline GO/PVA & Solution casting & 14 & $\begin{array}{c}\mathrm{Na}_{2} \mathrm{~S}_{2} \mathrm{O}_{4} / \mathrm{NaOH}, \\
60^{\circ} \mathrm{C}, 2 \mathrm{~h}\end{array}$ & 5.92 & [16] \\
\hline GO/PVA & Solution casting & 1.6 & $\begin{array}{l}\text { hydrazine } \\
\text { hydrate }\end{array}$ & $10^{-7}$ & [32] \\
\hline $\begin{array}{c}\text { Sulfonated } \\
\text { graphene/PVA }\end{array}$ & Solution casting & 5 & - & $1.5 \times 10^{-3}$ & [40] \\
\hline GO-PVA & Solution casting & 0.7 & $\begin{array}{l}\text { Thermal reduction } \\
\text { at } 200^{\circ} \mathrm{C}, 17 \mathrm{~min}\end{array}$ & $6.3 \times 10^{-3}$ & [41] \\
\hline GO-PVA & $\begin{array}{l}\text { Solution mixing and } \\
\text { filtration }\end{array}$ & 10 & $\begin{array}{c}\text { Hydrazine } \\
\text { hydrate, over night }\end{array}$ & $8 \times 10^{-4}$ & [42] \\
\hline GO-PVA & Solution casting & 50 & $\begin{array}{c}\mathrm{NaBH}_{4}, 80_{\mathrm{hr}}^{\circ} \mathrm{C}, 1.5 \\
\end{array}$ & $10^{-4}$ & [43] \\
\hline $\begin{array}{c}\text { Sulfonated } \\
\text { graphene/PVA }\end{array}$ & Solution casting & 50 & ---------------- & $10^{-2}$ & \\
\hline GO-PVA & Solution casting & $\begin{array}{c}1 \\
3 \\
10\end{array}$ & $\begin{array}{l}\text { Ehanol, } \mathrm{CO}_{2}(150 \\
\left.{ }^{\circ} \mathrm{C}, 200 \text { bar }\right), 2 \mathrm{~h}\end{array}$ & $\begin{array}{l}1.7 \\
14.2 \\
51.7\end{array}$ & $\begin{array}{l}\text { This } \\
\text { work }\end{array}$ \\
\hline
\end{tabular}

\section{Conclusion}

The graphene-polymer composite fiber/films can be fabricated using an environmentally friendly supercritical fluids assisted reduction method. The GO-PVA/PEG films/fiber are easily processable due to the hydrophilic nature of GO. The challenging task of reduction of GO in the composite film without degrading polymer can be achieved using a combination of $\mathrm{CO}_{2}$ and ethanol at $150{ }^{\circ} \mathrm{C}$ and 200 bar. Significant enhancement of the mechanical properties and electrical conductivity was obtained at very low loading of GO. While the electrically conducting graphene network in the polymer matrix is the key reason for the increased electrical conductivity after supercritical reduction, high loading of graphene was found to decrease the mechanical property of composite film. The demonstrated in situ supercritical fluid reduction strategy is very effective in low temperature reduction of GO in the polymer matrix without the cost of mechanical properties and yet industrially scalable and for this reason expected to find potential applications in graphene-polymer nanocomposite field. 


\section{Acknowledgments}

SPS is thankful to University of Bordeaux and the IdEx postdoctoral fellowship programme. This work has received financial support from the French State in the frame of the "Investments for the future" Programme IdEx Bordeaux, reference ANR-10-IDEX-03-02”. The authors declare no competing financial interest.

\section{References}

1. F. Bonaccorso, Z. Sun, T. Hasan, A.C. Ferrari. Graphene photonics and optoelectronics. Nat. Photon., 4 (2010), pp. 611-622.

2. A. Ambrosi, C.K. Chua, A. Bonanni, M. Pumera. Electrochemistry of graphene and related materials. Chem. Rev., 114 (2014), pp. 7150-7188.

3. M.J. Allen, V.C. Tung, R.B. Kaner. Honeycomb carbon: a review of graphene. Chem. Rev., 110 (2009), pp. 132-145.

4. J.D. Roy-Mayhew, I.A. Aksay. Graphene materials and their use in dye-sensitized solar cells. Chem. Rev., 114 (2014), pp. 6323-6348.

5. Y. Lee, J.-H. Ahn. Graphene-based transparent conductive films. Nano, 08 (2013), p. 1330001.

6. F. Schwierz. Graphene transistors. Nat. Nanotechnol., 5 (2010), pp. 487-496.

7. J.R. Potts, D.R. Dreyer, C.W. Bielawski, R.S. Ruoff. Graphene-based polymer nanocomposites. Polymer, 52 (2011), pp. 5-25.

8. Y. Sun, G. Shi. Graphene/polymer composites for energy applications. J. Polym. Sci. B Polym. Phys., 51 (2013), pp. 231-253.

9. J. Du, H.-M. Cheng. The fabrication, properties, and uses of graphene/polymer composites. Macromol. Chem. Phys., 213 (2012), pp. 1060-1077.

10. T. Kuilla, S. Bhadra, D. Yao, N.H. Kim, S. Bose, J.H. Lee. Recent advances in graphene based polymer composites. Prog. Polym. Sci., 35 (2010), pp. 1350-1375.

11. R.K. Layek, A.K. Das, M.J. Park, N.H. Kim, J.H. Lee. Enhancement of physical, mechanical, and gas barrier properties in noncovalently functionalized graphene oxide/poly(vinylidene fluoride) composites. Carbon, 81 (2015), pp. 329-338.

12. X. Cui, C. Zhang, R. Hao, Y. Hou. Liquid-phase exfoliation, functionalization and applications of graphene. Nanoscale, 3 (2011), pp. 2118-2126.

13. S. Stankovich, D.A. Dikin, G.H.B. Dommett, K.M. Kohlhaas, E.J. Zimney, E.A. Stach, R.D. Piner, S.T. Nguyen, R.S. Ruoff. Graphene-based composite materials. Nature, 442 (2006), pp. 282-286.

14. S. Stankovich, D.A. Dikin, R.D. Piner, K.A. Kohlhaas, A. Kleinhammes, Y. Jia, Y. Wu, S.T. Nguyen, R.S. Ruoff. Synthesis of graphene-based nanosheets via chemical reduction of exfoliated graphite oxide. Carbon, 45 (2007), pp. 1558-1565.

15. A. Elsagh. Enhanced electrical conductivity properties of Graphene Oxide nanocomposites functionalized with Polyvinyl Alcohol. Int. J. Nano Dimens. (IJND), 5 (2014), pp. 447-451.

16. J.-H. Yang, Y.-D. Lee. Highly electrically conductive rGO/PVA composites with a network dispersive nanostructure. J. Mater. Chem., 22 (2012), pp. 8512-8517.

17. L. Liu, Y. Gao, Q. Liu, J. Kuang, D. Zhou, S. Ju, B. Han, Z. Zhang. High mechanical performance of layered graphene oxide/poly (vinyl alcohol) nanocomposite films. Small, 9 (2013), pp. 2466-2472.

18. O.W. Guirguis, M.T.H. Moselhey. Thermal and structural studies of poly (vinyl alcohol) and hydroxypropyl cellulose blends. Nat. Sci., 4 (2012), p. 57.

19. M.T. Taghizadeh, N. Yeganeh, M. Rezaei. The investigation of thermal decomposition pathway and products of poly (vinyl alcohol) by TG-FTIR. J. Appl. Polym. Sci., 132 (2015).

20. M. Seo, D. Yoon, K.S. Hwang, J.W. Kang, J. Kim. Supercritical alcohols as solvents and reducing agents for the synthesis of reduced graphene oxide. Carbon, 64 (2013), pp. 207-218.

21. C. Gong, M. Acik, R.M. Abolfath, Y. Chabal, K. Cho. Graphitization of graphene oxide with ethanol during thermal reduction. J. Phys. Chem. C, 116 (2012), pp. 9969-9979.

22. S. Moussa, G. Atkinson, M. SamyEl-Shall, A. Shehata, K.M. AbouZeid, M.B. Mohamed. Laser assisted photocatalytic reduction of metal ions by graphene oxide. J. Mater. Chem., 21 (2011), pp. 9608-9619.

23. Y. Gu, H. Wu, Z. Xiong, W. Al Abdulla, X.S. Zhao. The electrocapacitive properties of hierarchical porous reduced graphene oxide templated by hydrophobic $\mathrm{CaCO}_{3}$ spheres. J. Mater. Chem., 2 (2014), pp. 451-459. 
46. S. Padmajan Sasikala, P. Poulin, C. Aymonier. Prospects of supercritical fluids in realizing graphene-based functional materials. Adv. Mater., 28 (2016), pp. 2663-2691.

47. S. Padmajan Sasikala, P. Poulin, C. Aymonier. Advances in subcritical hydro-/solvothermal processing of graphene materials. Adv. Mater., 29 (2017), pp. 1605473-1605505. 